\title{
Mechanical properties of kenaf bast and core fibre reinforced unsaturated polyester composites
}

\begin{abstract}
Kenaf fibre has high potential to be used for composite reinforcement in biocomposite material. It is made up of an inner woody core and an outer fibrous bark surrounding the core. The aim of this study was to compare the mechanical properties of short kenaf bast and core fibre reinforced unsaturated polyester composites with varying fibre weight fraction i.e. $0 \%$, $5 \%, 10 \%, 20 \%, 30 \%$ and $40 \%$. The compression moulding technique was used to prepare the composite specimens for tensile, flexural and impact tests in accordance to the ASTM D5083, ASTM D790 and ASTM D256 respectively. The overall results showed that the composites reinforced with kenaf bast fibre had higher mechanical properties than kenaf core fibre composites. The results also showed that the optimum fibre content for achieving highest tensile strength for both bast and core fibre composites was $20 \%$ wt. It was also observed that the elongation at break for both composites decreased as the fibre content increased. For the flexural strength, the optimum fibre content for both composites was $10 \%$ wt while for impact strength, it was at 10\%wt and 5\%wt for bast and core fibre composites respectively.
\end{abstract}

Keyword: Kenaf bast fibre; Kenaf core fibre; Mechanical properties 